\title{
Sedation Training Using a Human Patient Simulator
}

\author{
N. Hofmann ${ }^{\text {a }}$ C. Datz ${ }^{\text {b }}$ H. Schöchl ${ }^{c}$ \\ a Department of Anesthesiology and Intensive Care, Diakonissen-Krankenhaus, Salzburg, \\ ${ }^{b}$ Department of Internal Medicine, General Hospital Oberndorf, Oberndorf, and \\ ${ }^{'}$ Department of Anesthesiology and Intensive Care, AUVA Trauma Hospital, Salzburg, Austria
}

\section{Key Words}

High-fidelity simulation $\cdot$ Training $\cdot$ Sedation

\begin{abstract}
High-fidelity simulation uses simulators that combine all of the physiological and pharmacological responses of a human in a manikin. These simulators change and respond to the users and trainees. Using simulators for teaching sedation in the field of gastroenterology unifies all the advantages of manikins. To understand the pharmacological and pharmacodynamical principles of drugs used for sedation in different clinical scenarios, such as cardiopulmonary diseases, a high-fidelity simulator is extremely useful. Respiratory complications and airway problems are the main side effects when using sedatives. To overcome these problems, exercise of precautionary measures are highly demanded to avoid hazards. High-fidelity simulation is increasingly being used for the development of crisis resource management. There are still limitations in using simulators for education and training. At present, applying simulation for teaching is expensive. The start-up costs and the expenses for instructors and technicians are high. Moreover, no direct evidence has demonstrated that simulation training improves actual patient safety outcome and, therefore, a lot of research in this field remains to be done. Even so, confidence is growing in the validity of medical simulation as the training tool of the future.

Copyright $\odot 2010$ S. Karger AG, Basel
\end{abstract}

\section{Introduction}

Simulation, as defined by the Center for Medical Simulation, Cambridge, Mass., USA, is a situation or environment created to allow persons to experience a representation of a real event for the purpose of practicing, learning, evaluating, testing, or to gain understanding about systems or human actions. The field of simulation is now growing exponentially. At present more than 1,000 simulation centers have been established worldwide.

Simulation applications have become increasingly common in health care. Treating serious diseases, solving clinical problems and managing complications in health care, and especially hospital care, is associated with risks and hazards. In other industries with high hazards, like aviation, simulation plays an important role in education. As anesthesiologists have to manage a lot of different problems in the perioperative period, anesthesiology boards took the initiative to incorporate simulation in their education and postgraduate training programs. An interdisciplinary, multispecialty and international organization dedicated to the advancement of all types of simulation in health care was established in 2004 [1]. At the meeting of the American Society of Anesthesiologists (ASA) in Chicago, 2006, the new ASA Committee on Simulation Education was founded.

\section{KARGER}

Fax +4161306 1234

E-Mail karger@karger.ch

www.karger.com (c) 2010 S. Karger AG, Basel

$0012-2823 / 10 / 0822-0115 \$ 26.00 / 0$

Accessible online at:

www.karger.com/dig
Nikolaus Hofmann, MD

Department of Anesthesiology and Intensive Care

Diakonissen-Krankenhaus

AT-5026 Salzburg (Austria)

Tel. +43662 6385, Fax +436626385 485, E-Mail n.hofmann@ diakoniewerk.at 


\section{Development and Use of Simulators}

The first manikins, built by Asmund Laerdal, were introduced in the early 1960 s to teach mouth-to-mouth resuscitation and chest compression. Training programs pursuing the contemporary recommendations of the American Heart Association were launched [2]. The next step in developing simulators was the introduction of a computer-driven simulator called Sim One. This simulator even fasciculated after injecting succinylcholine. It was the first so-called 'high-fidelity simulator' because of its closeness to real life [3]. Advances in computer technology and mathematical programs for physiology and pharmacology led to the development of so-called 'human patient simulators'. These manikins combined all the physiological and pharmacological responses of a human being [4].

Simulator types are classified into three different categories: part-task trainers, computer-driven manikins and virtual reality simulators [5]. Part-task trainers are passive and are used for training specific skills, e.g. intubations or establishing venous access. Even more specific trainers were used in the field of endoscopy for teaching bronchoscopy as well as upper and lower gastrointestinal endoscopy. High-fidelity simulators not only possess anatomically correct features, but also recognize various stimuli, talk in an interactive manner and respond to medications through mathematical models. Integration of standardized patient methodology into these simulators increases the learning experience exponentially. The development of high-fidelity simulators is still at the beginning and there is yet a lot of work to be done.

\section{Sedation}

Sedation is the drug-induced depression of the level of consciousness. Different scales for the degree of sedation are used and the term 'continuum of sedation' describes the changes of consciousness which ranges from anxiolysis and moderate and deep sedation to general anesthesia [6]. In the United States, the majority of gastrointestinal procedures are performed under moderate sedation [7]. Sedation for endoscopy provides comfort to the patient and better examination conditions for the endoscopist [8].

The endoscopist should be able to distinguish moderate from deep levels of sedation and be aware of the different physiological responses concerning the vital or- gan systems, mainly the breathing and the cardiovascular system. Practice guidelines have been put forth by the ASA Committee for Sedation and Analgesia by NonAnesthesiologists [6]. The choice of sedative is largely operator-dependent and should be based on maximizing patient comfort while minimizing risks. Benzodiazepines, mainly midazolam (alone or in combination with opioids), are used. The drugs are usually administered by the endoscopist. Propofol, introduced in the 1980 s, is now used worldwide for sedation in endoscopy. Two methods have evolved for the administration of propofol under the direction of the practitioner: nurseadministered propofol sedation [9] and balanced propofol sedation or gastroenterologist-directed propofol sedation [10].

\section{Patient Evaluation and Risk Assessment}

The main problem during procedural sedation is compromising the respiratory function of the patient. Airway obstruction through the tongue base, soft palate or the epiglottis on the one hand and ventilatory depression mediated by sedatives on the other are the major problems. Patients with higher ASA status and obesity, as well as older patients, are at increased risk for developing hypoxemia during gastrointestinal procedures [11]. Long and complex procedures like ERCP or EUS are further risk factors for complications during sedation [12]. The knowledge of specific side effects and pharmacologic properties of the sedatives are essential for appropriate administration.

\section{Simulation in Endoscopy}

It was demonstrated that simulation in the field of endoscopy is extremely useful. Colonoscopy simulators are used worldwide and are part of many curricula in gastroenterology fellowships. Koch et al. [13] have demonstrated that the newer generations of simulators offer a convincing realistic representation of colonoscopy and that the simulator can discriminate between different levels of expertise. A study group in Mainz, Germany, combined a high-fidelity simulator with the Erlanger Endoscopy Trainer, and found that simulation was able to improve personal crisis management and led to an improvement of endoscopic and emergency skills [14]. 


\section{High-Fidelity Simulation for Sedation and Risk Management}

DeMaria et al. [15] offered a training session during the Conference of Endoscopic Sedation that included a full-scale patient simulator. Pre-procedure patient assessment, monitoring, pharmacological profile of sedatives, continuum of sedation and methods of rescue were able to be trained. The satisfaction of the attendees was rated as excellent [15]. High-fidelity simulation is becoming an important tool for education and training in acute areas, like trauma resuscitation, where initial management and therapeutic interventions are critical. In an article by Knudson et al. [16], two groups of surgical residents were randomized to receive a scenario-based trauma curriculum. The first group was assigned were to receive a didactic lecture and the second group the use of a human performance simulator. After a written learning objectives test, the first four trauma resuscitations performed by each participating resident were captured on videotape in the emergency department and graded by two experienced judges blinded to the method of training. The simulator-trained group received higher overall scores and higher scores for crisis management skills [16].
High-fidelity simulation seems to be the tool of choice for teaching how to facilitate adequate sedation and manage sedation-related complications and overall assessment, as clinical scenarios can be reproduced, complications and crisis management can be discussed, and opportunities for improvement and further practice can be suggested. After simulation training, communication, leadership, teamwork and decision-making should be discussed in a debriefing session.

\section{Conclusions}

Despite the advances of implementing simulation in education and training, there are still some limitations. At present, using simulation for teaching is expensive. The start-up costs and the expenses for instructors and technicians are high. Moreover, no direct evidence has demonstrated that simulation training improves actual patient safety outcome; therefore, a lot of research in this field remains to be done. Even so, confidence is growing in the validity of medical simulation as the training tool of the future.

\section{References}

1 Society for Simulation in Health Care. http:// ssih.org.

2 Grevnik A, Schaefer J: From Resusci-Anne to Sim Man: the evolution of simulators in medicine. Crit Care Med 2004;32(suppl 2):S56-S57.

$>3$ Denson J, Abrahamson S: A computer-controlled patient simulator. JAMA 1969;208: 504-508.

4 METI Web site. www.meti.com/products.

5 Scalese RJ, Obeso VT, Issenberg SB: Simulation technology for skills training and competency assessment in medical education. J Gen Intern Med 2007;23:46-49.

6 American Society of Anesthesiologists Task Force on Sedation and Analgesia by NonAnesthesiologists: Practice guidelines for sedation and analgesia by non-anesthesiologists. Anesthesiology 2002;96:1004-1017.
7 American Society for Gastrointestinal Endoscopy: Guidelines for conscious sedation and monitoring during gastrointestinal endoscopy. Gastrointest Endosc 2003;58:317322.

8 Radaelli F, Meucci G, Sgroi G, et al: Technical performance of colonoscopy: the key role of sedation/analgesia and other quality indicators. Am J Gastroenterol 2008;103:11221130.

-9 Rex DK, Heuss LT, Walker JA, et al: Trained registered nurses/endoscopy teams can administer propofol safely for endoscopy. Gastroenterology 2005;129:1384-1391.

10 Cohen LB, Dubovsky AN, Aisenberg J, et al: Propofol for endoscopic sedation: a protocol for safe and effective administration by the gastroenterologist. Gastrointest Endosc 2003;58:725-732.

11 Vargo JJ, Holub JL, Faigel Do, et al: Risk factors for cardiopulmonary events during propofol-mediated upper endoscopy and colonoscopy. Aliment Pharmacol Ther 2006;24: 955-963.
12 Patel S, Vargo JJ, Khandwala F, et al: Deep sedation occurs frequently during elective endoscopy with meperidine and midazolam. Am J Gastroenterol 2005;100:2689-2695.

13 Koch Ad, Buzink SN, Heemskerk J, et al: Expert and construct validity of the Simbionix GI Mentor II endoscopy simulator for colonoscopy. Surg Endosc 2008;22:158-162.

14 Kiesslich R, Moenk S, Reinhardt K, et al: Combined simulation training: a new concept and workshop is useful for crisis management in gastrointestinal endoscopy. Z Gastroenterol 2005;43:1031-1039.

15 DeMaria S, Levine AI, Cohen LB: Human patient simulation and its role in endoscopic sedation training. Gastrointest Endoscopy Clin N Am 2008;18:801-813.

16 Knudson MM, Khaw L, Bullard K, et al: Trauma training in simulation: translating skills from Sim to real time. J Trauma 2008; 64:255-264. 